\title{
Epidemiology and impact of multimorbidity in primary care: a retrospective cohort study
}

\author{
Chris Salisbury, Leigh Johnson, Sarah Purdy, Jose M Valderas and Alan A Montgomery
}

\section{ABSTRACT}

\section{Background}

In developed countries, primary health care increasingly involves the care of patients with multiple chronic conditions, referred to as multimorbidity.

Aim

To describe the epidemiology of multimorbidity and relationships between multimorbidity and primary care consultation rates and continuity of care.

Design of study

Retrospective cohort study.

Setting

Random sample of 99997 people aged 18 years or over registered with 182 general practices in England contributing data to the General Practice Research Database.

\section{Method}

Multimorbidity was defined using two approaches: people with multiple chronic conditions included in the Quality and Outcomes Framework, and people identified using the Johns Hopkins University Adjusted Clinical Groups (ACG ${ }^{\circledR}$ ) Case-Mix System. The determinants of multimorbidity (age, sex, area deprivation) and relationships with consultation rate and continuity of care were examined using regression models.

\section{Results}

Sixteen per cent of patients had more than one chronic condition included in the Quality and Outcomes

Framework, but these people accounted for $32 \%$ of all consultations. Using the wider ACG list of conditions, $58 \%$ of people had multimorbidity and they accounted for $78 \%$ of consultations. Multimorbidity was strongly related to age and deprivation. People with multimorbidity had higher consultation rates and less continuity of care compared with people without multimorbidity.

\section{Conclusion}

Multimorbidity is common in the population and most consultations in primary care involve people with multimorbidity. These people are less likely to receive continuity of care, although they may be more likely to gain from it.

\section{Keywords}

chronic disease; comorbidity; family practice; primary health care; outcome and process assessment (healthcare); prevalence.

\section{INTRODUCTION}

The practice of medicine is becoming increasingly specialised, both in hospitals and in general practice. For example, many practices now offer chronic disease management clinics for conditions such as diabetes. This approach of treating each condition in isolation has serious limitations. It is important to recognise that many people have multiple coexisting chronic medical conditions, or 'multimorbidity'. ${ }^{1}$ People with multimorbidity are likely to have complex needs for health care and to account for a high proportion of the healthcare workload. Increased understanding of the epidemiology and impact of multimorbidity is needed to inform the way in which health care is organised and delivered.

The basis of primary care is that generalists manage all health problems commonly occurring in the population, identifying and referring those problems needing specialist care, and coordinating care for patients with complex health problems. ${ }^{2}$ However, efforts to improve quality of care have fuelled a move towards specialisation within general

C Salisbury, MD, FRCGP, professor of primary health care; L Johnson, MSc, research associate; S Purdy, MD, FRCGP, consultant senior lecturer; $A A$ Montgomery, $P h D$, reader in health services research, Department of Community Medicine, University of Bristol and NIHR School for Primary Care Research. JM Valderas, PhD, MPH, academic clinical lecturer, Division of Public Health and Primary Health Care, University of Oxford and NIHR School for Primary Care Research.

Address for correspondence

Professor Chris Salisbury, School of Social and Community Medicine, University of Bristol, Canynge Hall, 39 Whatley Road, Bristol BS8 2PS. E-mail: c.salisbury@bristol.ac.uk

Submitted: 9 April 2010; Editor's response: 4 May 2010; final acceptance: 25 May 2010.

(C) British Journal of General Practice

This is the full-length article (published online 27 Dec 2010) of an abridged version published in print. Cite this article as: Br J Gen Pract 2011; DOI: 10.3399/bjgp11X548929. 
practice, and an emphasis on improving access has led to a multiplicity of providers, with patients being less likely to consult the same professional on each occasion.

It is important to consider how the balance should be struck between care provided by professionals with generalist training, able to tackle a wide range of problems at one consultation, or care provided by a wide range of specialists with cross-referral between themselves. This debate needs to be informed by data about the extent and nature of multimorbidity in patients consulting in primary care.

Several studies have examined the prevalence of multimorbidity in different countries. These have reached varied conclusions as a result of differences in setting, the range of health conditions included, and data sources. ${ }^{3-5}$ Some studies have been based on surveys or administrative data, or have been restricted to older populations. ${ }^{6,7}$ Most studies based on medical records have involved relatively small numbers of practices and/or patients, ${ }^{3}$ while larger studies have focused on the determinants and prevalence of multimorbidity, ${ }^{8-12}$ but few have related this to process or outcome variables in primary care. ${ }^{13,14}$ Earlier research on multimorbidity has been limited by problems with case definition and with the reliability of data recording within routine practice records. ${ }^{15}$ There is little information about the epidemiology of multimorbidity in the UK.

The almost universal computerisation of general practice records in the UK over the last 20 years has been accompanied by the development of research databases that combine quality-assured data from a large and representative range of practices. In addition, the introduction of the Quality and Outcomes Framework (QOF) has led to the consistent recording of diagnoses of many important chronic health conditions. These factors enable population-based research into multimorbidity. The aims of this study were to gain a detailed and reliable understanding of the epidemiology of multimorbidity in England, and relationships between multimorbidity, consultation rate, and longitudinal continuity in primary care.

\section{METHOD}

\section{Sample}

This study is based on the anonymised records of a random sample of 99997 adult patients (aged 18 years or over) from 182 practices in England contributing data to the General Practice Research Database (GPRD). These were all the practices in the GPRD that had provided 'research standard' data continuously from 1 April 2005 to 31 March 2008, and had given consent to link their data to measures

\section{How this fits in}

Several studies have described the prevalence and determinants of

multimorbidity, but these have produced varied results. There is little published

information on the prevalence of multimorbidity in the UK. Computerisation of

general practice records in the UK along with reliable coding of many chronic

diseases, due to the Quality and Outcomes Framework, have made it possible

to obtain reliable estimates of multimorbidity. This study shows that

multimorbidity is very common in the population, particularly in older people

and those living in deprived areas. The majority of consultations in general

practice involve people with multimorbidity. People with multimorbidity are

frequent users of primary care and are less likely to receive continuity of care.

These findings support the importance of people having access to a generalist

primary care service that is able to coordinate care for a wide range of

problems in one individual.

of area deprivation. Patients were eligible for inclusion if they were aged 18 years or over and were registered with one of the participating practices on the index date of 1 April 2005. Sample selection was stratified by practice, age group, and sex. Data were obtained with regard to all diagnoses, consultations, and prescriptions entered until 31 March 2008, including both diagnoses entered contemporaneously and earlier diagnoses that had been entered retrospectively by practices from earlier paper notes.

\section{Defining multimorbidity}

Multimorbidity was operationalised in two ways. The primary approach was to define it as a patient who, on the index date, had more than one of 17 important chronic conditions for which care is incentivised under the QOF (Box 1). The QOF business rules ${ }^{16}$ specify the Read Codes which are used to define each condition. These rules were applied to the diagnostic codes within the GPRD data to determine whether or not individuals had each chronic condition.

As in the QOF itself, patients were included if they had ever had the condition unless there was a code to indicate that it had resolved. The advantage of this approach is that recording of QOF conditions is likely to be reliable and complete, as recording is linked to payments to practices, and case definition is well defined. However, although these 17 conditions include many of the most important chronic conditions, many others are not included (for example, skin disease and liver disease). Therefore, this approach underestimates the true prevalence of multimorbidity.

As a secondary approach, the Johns Hopkins University Adjusted Clinical Groups (ACG ${ }^{\circledR}$ ) Case-Mix System ${ }^{17}$ was used to identify whether or not each patient had one or more of a much wider list of 
Box 1. Chronic conditions included in the Quality and Outcomes Framework and counted within the definition of multimorbidity.

- Asthma

- Atrial fibrillation

- Cancer

- Coronary heart disease

- Chronic kidney disease

- Chronic obstructive airways disease

- Dementia

- Depression

- Diabetes

- Epilepsy

- Heart failure

- Hypertension

- Learning disability

- Mental health problem (psychosis, schizophrenia, or bipolar affective disorder)

- Obesity

- Stroke

- Thyroid disease

chronic conditions. One problem with operationalising multimorbidity based on a count of chronic diseases entered in routine medical records is that the same disease may be coded in different ways and therefore counted twice in the same individual. The ACG system uses a software programme to collapse a wide range of diagnostic codes found within patients' records into 260 mutually exclusive clinically homogeneous 'expanded diagnostic clusters' (EDCs).

Three investigators, all of whom are GPs, independently assessed whether each of the diagnostic clusters should be included as a chronic condition. Differences were resolved by consensus. A chronic condition was defined as one that normally lasts 6 months or more, including past conditions that require ongoing disease or risk management, important conditions with a significant risk of recurrence, or past conditions that have continuing implications for patient management. In this way, 114 of the 260 diagnostic clusters were defined as chronic conditions (Appendix 1).

The ACG software was used in conjunction with the diagnostic data in the GPRD dataset to determine whether or not each patient had ever been diagnosed with each condition, and an EDC-based chronic condition count per patient was calculated.

\section{Analysis}

The prevalence of multimorbidity was estimated in relation to age, sex, and deprivation. Agestandardised prevalence estimates were calculated using the European Standard Population. ${ }^{18}$ Deprivation was based on Townsend scores derived from the patient's postcode and national quintiles using 2001 census data. Based on previous research, it was anticipated that multimorbidity would show a positive association with age, female sex, and deprivation. $3 ., 8,12,19,20$

The study sought to investigate associations between multimorbidity, consultation rates, and continuity of care. Consultation rates were calculated over 3 years beginning 1 April 2005, and were based on consultations with GPs or practice nurses, including face-to-face and telephone consultations. Annual rates were calculated, taking account of patients who left the practice or died during the period studied. Using the total number of consultations (rather than the number of patients) as the denominator, the proportion of consultations that involved patients with different levels of multimorbidity was also explored.

Longitudinal continuity of care over 3 years was calculated, making use of the fact that each consultation in the GPRD dataset has identifiers to indicate type of consultation, which clinician conducted it, and that clinician's profession. The usual provider continuity inde ${ }^{21}$ and the continuity of care index ${ }^{22}$ were calculated. The usual provider continuity index represents the proportion of all consultations with the clinician who had been consulted most often, and the continuity of care index is a measure of the concentration of consultations with different doctors, adjusting for the number of consultations. Face-to-face and telephone consultations with GPs or practice nurses were included in continuity analyses. Patients with fewer than two consultations in the 3-year period were excluded.

\section{Statistical analysis}

For both the QOF and the ACG/EDC approaches, all analyses were repeated treating multimorbidity as a binary variable (none or one chronic condition versus more than one) and also as a discrete variable (number of conditions). Descriptive statistics, including 95\% confidence intervals, were used to describe relationships between multimorbidity and other variables. Independent relationships between age, sex, deprivation, and multimorbidity when treated as a binary or discrete variable, were examined using logistic and Poisson regressions respectively. Consultation rate data were skewed and were therefore log transformed 
before being included in multiple linear regression analyses with multimorbidity, age, sex, and deprivation as explanatory variables. Relationships between multimorbidity and continuity of care were similarly examined. All analyses were conducted in Stata (version 11.0). The 'svy' survey commands were used throughout to take account of the sampling methods.

\section{RESULTS}

\section{Epidemiology of multimorbidity}

Initial examination of the patient sample in comparison with census data indicated that it was representative of the population of England in terms of age-sex distribution, although with slightly lower levels of deprivation (mean Townsend score = $-1.04)$.

By the index date, $16 \%$ of the sample (16 030/99 997) had been diagnosed with more than one of the conditions included in the QOF, but $58 \%$ (58 115/99 997) had been diagnosed with more than one EDC chronic condition. The age-standardised prevalence was 14\% using the QOF approach and $56 \%$ using the ACG/EDC approach.

Figure 1 demonstrates that multimorbidity is strongly related to age, and slightly more common in females than males below the age of 65 years. Patients aged 75 years or over had mean $=1.56$ $(95 \% \mathrm{Cl}=1.52$ to 1.59$)$ QOF conditions and mean = $5.63(95 \% \mathrm{Cl}=5.52$ to 5.74$)$ EDC conditions. Figure 2 illustrates that $77 \%$ of patients aged 75 years or over had at least one QOF condition, $44 \%$ had more than one QOF condition (multimorbidity), and $9 \%$ had four or more conditions.

Table 1 shows that increasing age, female sex, and living in a deprived area were all, as hypothesised, independently associated with increased odds of having multimorbidity. Patients in the most deprived quintile for deprivation were almost twice as likely to have multimorbidity as those in the least deprived quintile (odds ratio 1.91 [95\% $\mathrm{Cl}=1.78$ to 2.04$]$ adjusted for age and sex). Similar results were observed with the ACG/EDC approach, although the relationship with deprivation was less marked.

\section{Multimorbidity and consultation rates}

The overall consultation rate was $4.63(95 \% \mathrm{Cl}=$ 4.58 to 4.69 ) consultations per patient per annum. Consultation rates showed the anticipated relationships with age, sex, and deprivation, with increasing rates with age, higher consultation rates for females than males among those below the age of 65 years, and higher rates in more deprived areas. Patients with multimorbidity (based on QOF) had $9.35(95 \% \mathrm{Cl}=9.21$ to 9.49$)$ consultations per

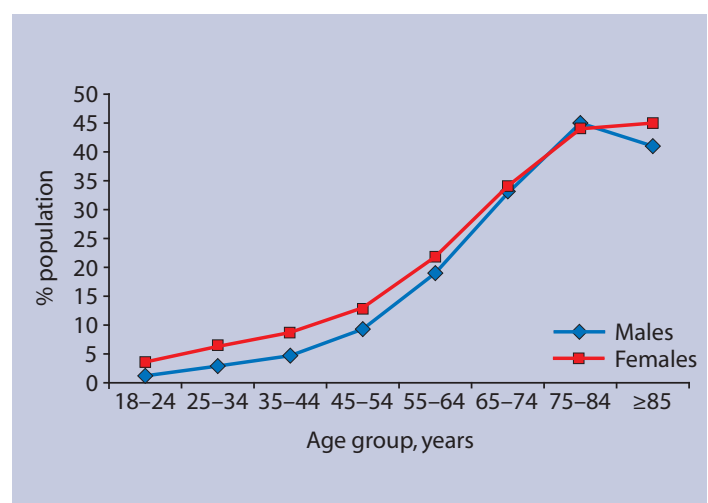

Figure 1. Percentage of population with more than one chronic condition in the Quality and Outcomes Framework, by age and sex.

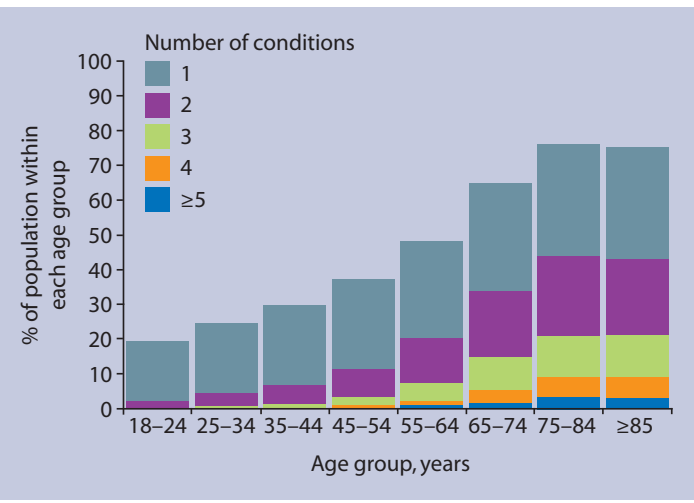

Figure 2. Number of conditions included in the Quality and Outcomes Framework, per patient, by age group.
Table 1. Independent associations between multimorbidity ${ }^{a}$ and age, sex, and deprivation.

\begin{tabular}{|c|c|c|c|}
\hline Variable & Odds ratio & $95 \%$ confidence interval & $P$-value \\
\hline $\begin{array}{l}\text { Age (per } 10 \text {-year increase; } \\
\text { range } \geq 18 \text { years) }\end{array}$ & 1.78 & 1.76 to 1.81 & $<0.001$ \\
\hline Sex (reference category: male) & 1.23 & 1.18 to 1.28 & $<0.001$ \\
\hline $\begin{array}{l}\text { Deprivation (per 10-unit } \\
\text { increase in Townsend score) }\end{array}$ & 2.08 & 1.95 to 2.22 & $<0.001$ \\
\hline
\end{tabular}

aultimorbidity is defined as having more than one condition in the Quality and Outcomes Framework. All variables are adjusted for each other. $\mathrm{n}=99624$ due to missing deprivation data for 373 individuals.

annum compared with $3.75(95 \% \mathrm{Cl}=3.71$ to 3.80$)$ among those without multimorbidity.

Table 2 shows the independent relationships between consultation rate and age, sex, and deprivation before and after adjusting for multimorbidity. It demonstrates that the relationship between age and consultation rate is reduced, and that between deprivation and consultation rate almost disappears, after adjustment for multimorbidity. This suggests that the main reason that older patients and those in deprived areas consult more often is because they have more chronic health conditions.

\section{Proportion of consultations involving patients with multimorbidity}

Using all consultations between 1 April 2005 and 31 
Table 2. Independent relationships between age, sex, deprivation, and consultation rate, before and after adjusting for multimorbidity.

\begin{tabular}{|c|c|c|c|c|c|c|}
\hline \multirow[b]{3}{*}{ Explanatory variable } & \multicolumn{6}{|c|}{ Consultation rate } \\
\hline & \multicolumn{3}{|c|}{$\begin{array}{l}\text { Before adjustment for } \\
\text { multimorbidity } R^{2}=0.19\end{array}$} & \multicolumn{3}{|c|}{$\begin{array}{c}\text { After adjustment for } \\
\text { multimorbidity } R^{2}=0.30\end{array}$} \\
\hline & Coefficient & $95 \% \mathrm{Cl}$ & $P$-value & Coefficient & $95 \% \mathrm{Cl}$ & $P$-value \\
\hline $\begin{array}{l}\text { Age (per } 10 \text {-year increase; } \\
\text { range } \geq 18 \text { years) }\end{array}$ & 0.17 & 0.17 to 0.18 & $<0.001$ & 0.09 & 0.09 to 0.10 & $<0.001$ \\
\hline Sex (reference category: male) & 0.48 & 0.46 to 0.50 & $<0.001$ & 0.42 & 0.40 to 0.44 & $<0.001$ \\
\hline $\begin{array}{l}\text { Deprivation (per 10-unit increase } \\
\text { in Townsend score) }\end{array}$ & 0.12 & 0.10 to 0.15 & $<0.001$ & 0.03 & 0.01 to 0.05 & 0.01 \\
\hline $\begin{array}{l}\text { Multimorbidity (number of QOF } \\
\text { chronic conditions) }\end{array}$ & - & - & $<0.001$ & 0.37 & 0.36 to 0.38 & $<0.001$ \\
\hline
\end{tabular}

All variables were adjusted for each other. $\mathrm{n}=99624$ due to missing deprivation data for 373 individuals. QOF = Quality and

Outcomes Framework.

March 2008 as the denominator $(n=1430773)$, rather than the number of patients, the proportion of primary care consultations that involved people with multimorbidity was explored. Although patients with multimorbidity (QOF) represented only $16 \%$ of the population, they accounted for $32 \%$ of all consultations. Using the ACG/EDC approach, 58\% of patients had multimorbidity, and these individuals accounted for $78 \%$ of all consultations.

Figure 3 shows the number of different chronic conditions encountered by primary care practitioners in an average consultation, in relation to patients' age. Consultations with patients aged over 75 years involved individuals with mean $=1.86(95 \% \mathrm{Cl}=1.82$ to 1.91$)$ QOF conditions and $6.68(95 \% \mathrm{Cl}=6.53$ to 6.82) EDC conditions.

\section{Multimorbidity and continuity of care}

Levels of longitudinal continuity of care were low for all patients (mean $=0.25$ on both indices). QOF multimorbidity was inversely associated with the usual provider continuity index (coefficient -0.08 [95\% $\mathrm{Cl}=-0.09$ to -0.08$]$ after adjusting for age, sex, and deprivation). The equivalent model using the continuity of care index (which takes account of the number of consultations) showed a much smaller but

Figure 3. Number of chronic conditions in patients consulting, per consultation, by age group. $E D C=$ expanded diagnostic clusters from the Johns Hopkins University Adjusted Clinical Groups (ACG) Case-Mix System. ${ }^{17}$ QOF = Quality and Outcomes Framework. still inverse relationship between multimorbidity and longitudinal continuity (coefficient $=-0.008[95 \% \mathrm{Cl}$ $=-0.011$ to -0.004$])$.

\section{DISCUSSION}

\section{Summary of main findings}

Most consultations in primary care involve patients with multimorbidity. These people have reduced longitudinal continuity of care, largely because of their high consultation rates. Although multimorbidity is common, the estimated prevalence varies considerably, depending on how it is measured. Prevalence increases with age, but affects patients of all age groups. Multimorbidity is more common among patients living in deprived areas.

\section{Strengths and limitations of the study}

This article is based on a larger and more representative sample than earlier studies of the epidemiology of multimorbidity. As almost everyone in the UK is registered with just one general practice, participants are broadly equivalent to a population sample. The introduction of the QOF means that the coding of important diseases is likely to be consistent across participating practices, and the development of case-mix software such as the ACG system overcomes some of the coding problems encountered by previous studies. $^{23}$ The comprehensive nature of the data recorded with the GPRD makes it possible to explore relationships between multimorbidity and health processes and outcomes. This paper also builds on previous research by highlighting the high proportion of consultations that involve people with multimorbidity, which is important from a health-system perspective.

The study has several limitations. The large sample means that it is important to consider the magnitude of associations rather than $P$-values. The difference between the findings obtained using the 
QOF or ACG/EDC approaches illustrates the difficulty of providing precise estimates of the prevalence of multimorbidity, as this depends on the range of conditions included. Because the QOF approach only includes a limited number of conditions, it underestimates prevalence. The ACG/EDC approach includes a comprehensive list of chronic conditions, but in the absence of an internationally recognised list of conditions defined as chronic, the authors had to generate their own, and other investigators may have identified a different list. ${ }^{24}$ In addition, not all of the 'chronic' conditions included may have been active or relevant in a particular patient. The prevalence of multimorbidity should therefore always be stated in relation to the measure used.

Both the QOF and the ACG/EDC approaches represent disease counts, with each disease counted equally. Case-mix adjustment methods that weight diseases differentially to estimate the burden of illness (such as the Charlson index ${ }^{25}$ or the full ACG system ${ }^{17}$ ) are likely to predict outcomes more effectively, ${ }^{1}$ but, unlike a disease count, they do not provide a direct measure of multimorbidity as usually defined in terms of multiple conditions. Furthermore, this paper is based on a definition of multimorbidity as the coexistence of multiple diseases. This approach provides a limited and medicalised perspective, which may not reflect patients' understanding of their problems. ${ }^{1}$

Estimates of multimorbidity in this study are based on diagnoses recorded in medical records. Different estimates of prevalence are obtained using different sources of data, such as GP records, patient surveys, or studies involving examination of patient cohorts. ${ }^{5,26}$ Studies based on medical records will underestimate multimorbidity because some diseases are undiagnosed, and because they will not identify people who do not consult. Conversely, the relationship between multimorbidity and consultation rate has a risk of circularity, in that people who consult more often may have more conditions diagnosed. ${ }^{27}$

\section{Comparison with existing literature}

This study supports previous research with regard to the strong relationships between multimorbidity and increasing age $\mathrm{e}^{3,8,12}$ and social disadvantage. .,12,20 $^{2}$ Previous studies have examined the relationship between multimorbidity and hospitalisation, but few have explored the relationship with utilisation of primary care, and these studies are not directly comparable. ${ }^{28-30}$ Apart from a small study in just one practice ${ }^{31}$ it was not possible to identify any previous research examining the relationship between multimorbidity and continuity of care.
This paper adds to previous literature because of the size and generalisability of the sample, the reliability of the data sources, and the comparison of different approaches to measuring multimorbidity. It is also the first comprehensive published study of multimorbidity in the UK.

\section{Implications for clinical practice and future research}

Most consultations in primary care involve patients with multiple conditions, and these may need to be taken into account when making decisions about patient management. Interactions between the conditions may further complicate decision making. ${ }^{1}$ Guidelines are available to inform the management of many chronic diseases but these often fail to offer clear guidance about patients with comorbidities. ${ }^{32}$ Therefore, practitioners working in primary health care need to have a broad knowledge base, be able to coordinate care across a wide range of different specialist services, have excellent communication skills to manage complex consultations in a limited time, and have good judgment to balance competing priorities.

Given that so many patients have multiple chronic conditions, healthcare systems that are based on first-contact specialist care are likely to result in patients having frequent consultations in different locations or with different providers and often seeing practitioners who have to cross-refer to other specialists for advice about comorbidities. Systems that fragment care across multiple primary care providers face challenges in coordinating care for the many patients with multiple problems.

Continuity of care is particularly important to people with multimorbidity, ${ }^{33,34}$ but this study demonstrates that these people are less likely to receive it. Longitudinal continuity, as measured here, is closely related to relational continuity, ${ }^{34}$ and although better coordination between providers and shared records may enhance 'management continuity' and 'information continuity', ${ }^{35}$ it should not be assumed that these can substitute for the relationship with a particular doctor that many people with multimorbidity value..$^{33,34,36}$

Multimorbidity should be considered as a possible confounding factor in studies comparing the process or outcomes of care in different settings. Although multimorbidity is very common, it is not known how best to organise health services in order to optimise care for these people. A better understanding of the problems that multimorbidity generates is needed to develop and test interventions to improve care.

\section{Funding body}

This work was undertaken by the authors, who received funding from the National Institute for Health Research 
(NIHR) School for Primary Care Research funding scheme. This report presents independent commissioned research by the National Institute for Health Research. The views expressed in this publication are those of the authors and not necessarily those of the NHS, the NIHR, or the Department of Health. This study is based in part on data from the Full Feature General Practice Research Database obtained under licence from the UK Medicines and Healthcare Products Regulatory Agency. However the interpretation and conclusions contained in this study are those of the authors alone. Access to the GPRD database was funded through the Medical Research Council's licence agreement with MHRA.

\section{Ethics committee}

Studies based on the GPRD are covered by ethics approval granted by Trent Multicentre Research Ethics Committee, reference 05/MRE04/87.

\section{Competing interests}

The authors have stated that there are none.

\section{Acknowledgements}

We would like to thank members of the multimorbidity theme group within the National School for Primary Care Research for constructive criticism on this research as it was designed and presented.

\section{Discuss this article}

Contribute and read comments about this article on the Discussion Forum: http://www.rcgp.org.uk/bjgp-discuss

\section{REFERENCES}

1. Valderas JM, Starfield B, Sibbald B, et al. Defining comorbidity: implications for understanding health and health services. Ann Fam Med 2009; 7(4): 357-363.

2. Starfield B. Primary care - balancing health needs, services, and technology. Oxford: Oxford University Press, 1998.

3. Fortin M, Bravo G, Hudon C, et al. Prevalence of multimorbidity among adults seen in family practice. Ann Fam Med 2005; 3(3): 223-228.

4. Van den Akker M, Buntinx F, Roos S, Knottnerus JA. Problems in determining occurrence rates of multimorbidity. J Clin Epidemiol 2001; 54(7): 675-679.

5. Schram MT, Frijters D, van de Lisdonk EH, et al. Setting and registry characteristics affect the prevalence and nature of multimorbidity in the elderly. J Clin Epidemiol 2008; 61(11): 1104-1112.

6. Hoffman C, Rice D, Sung HY. Persons with chronic conditions. Their prevalence and costs. JAMA 1996; 276(18): 1473-1479.

7. Starfield B, Lemke KW, Bernhardt T, et al. Comorbidity: implication for the importance of primary care in 'case' management. Ann Fam Med 2003; 1(1): 8-14.

8. Van den Akker M, Buntinz F, Metsemakers JF, et al. Multimorbidity in general practice: prevalence, incidence, and determinants of cooccurring chronic and recurrent diseases. J Clin Epidemiol 1998; 51(5): $367-375$.

9. Saltman DC, Sayer GP, Whicker SD. Co-morbidity in general practice. Postgrad Med J 2005; 81(957): 474-480.

10. Schellevis FG, van der Velden J, van de Lisdonk E, et al. Comorbidity of chronic diseases in general practice. J Clin Epidemiol 1993; 46(5): 469-473.

11. Hippisley-Cox J, Pringle M. Comorbidity of diseases in the New General Medical Services Contract for General Practitioners: analysis of QRESEARCH data. Nottingham: QRESEARCH, 2007. http://www.qresearch.org/Public_Documents/DataValidation/Comorbidity $\% 20$ of $\% 20$ diseases $\% 20$ in $\% 20$ the $\% 20$ new $\% 20$ GMS $\% 20$ con tract\%20for\%20GPs.pdf (accessed 15 Oct 2010).

12. Britt HC, Harrison CM, Miller GC, Knox SA. Prevalence and patterns of multimorbidity in Australia. Med J Aust 2008; 189(2): 72-77.

13. Reid R, Evans R, Barer M, et al. Conspicuous consumption: characterizing high users of physician services in one Canadian province. J Health Serv Res Policy 2003; 8(4): 215-224.

14. Fortin M, Lapointe L, Hudon C, Vanasse A. Multimorbidity is common to family practice. Is it commonly researched? Can Fam Physician 2005; 51: 244-245.

15. Van den Akker M, Buntinx F, Roos S, Knottnerus JA. Problems in determining occurrence rates of multimorbidity. J Clin Epidemiol 2001; 54(7): 675-679.
16. NHS Primary Care Commissioning. QOF implementation business rules $v 11$. http://www.primarycarecontracting.nhs.uk/145.php (accessed 15 Oct 2010).

17. The John Hopkins University ACG case-mix system. http://www.acg.jhsph.edu/html/International.htm (accessed 15 Oct 2010).

18. Office for National Statistics. Distribution of the European standard population, 1998. http://www.statistics.gov.uk/STATBASE/ xsdataset.asp?vlnk=1260\&More $=\mathrm{Y}$ (accessed 15 Oct 2010).

19. Uijen AA, van de Lisdonk EH. Multimorbidity in primary care: prevalence and trend over the last 20 years. Eur J Gen Pract 2008; 14(suppl 1): 28-32.

20. Macleod U, Mitchell E, Black M, Spence G. Comorbidity and socioeconomic deprivation: an observational study of the prevalence of comorbidity in general practice. Eur J Gen Pract 2004; 10(1): 24-26.

21. Breslau N, Reeb KG. Continuity of care in a university-based practice. $J$ Med Educ 1975; 50(10): 965-969.

22. Bice TW, Boxerman SB. A quantitative measure of continuity of care. Med Care 1977; 15(4): 347-349.

23. Van den Akker M, Buntinx F, Roos S, Knottnerus JA. Problems in determining occurrence rates of multimorbidity. J Clin Epidemiol 2001; 54(7): 675-679.

24. O'Halloran J, Miller GC, Britt H. Defining chronic conditions for primary care with ICPC-2. Fam Pract 2004; 21(4): 381-386.

25. Charlson ME, Pompei P, Ales KL, MacKenzie CR. A new method of classifying prognostic comorbidity in longitudinal studies: development and validation. J Chronic Dis 1987; 40(5): 373-383.

26. Esteban-Vasallo MD, Dominguez-Berjon MF, Astray-Mochales J, et al. Epidemiological usefulness of population-based electronic clinical records in primary care: estimation of the prevalence of chronic diseases. Fam Pract 2009; 26(6): 445-454.

27. Perkins AJ, Kroenke K, Unutzer J, et al. Common comorbidity scales were similar in their ability to predict health care costs and mortality. $J$ Clin Epidemiol 2004; 57(10): 1040-1048.

28. Starfield B, Lemke KW, Herbert R, et al. Comorbidity and the Use of Primary Care and Specialist Care in the Elderly. Ann Fam Med 2005; 3(3): 215-222.

29. Tooth L, Hockey R, Byles J, Dobson A. Weighted multimorbidity indexes predicted mortality, health service use, and health-related quality of life in older women. J Clin Epidemiol 2008; 61(2): 151-159.

30. Reid R, Evans R, Barer M, et al. Conspicuous consumption: characterizing high users of physician services in one Canadian province. J Health Serv Res Policy 2003; 8(4): 215-224.

31. Sturmberg JP. Morbidity, continuity of care and general practitione workload: Is there a connection? Asia Pac Fam Med 2002; 1: 12-17.

32. Van Weel C, Schellevis FG. Comorbidity and guidelines: conflicting interests. Lancet 2006; 367(9510): 550-551.

33. Bayliss EA, Edwards AE, Steiner JF, Main DS. Processes of care desired by elderly patients with multimorbidities. Fam Pract 2008; 25(4): 287-293.

34. Cowie L, Morgan M, White P, Gulliford M. Experience of continuity of care of patients with multiple long-term conditions in England. J Health Serv Res Policy 2009; 14(2): 82-87.

35. Haggerty JL, Reid RJ, Freeman GK, et al. Continuity of care: a multidisciplinary review. BMJ 2003; 327(7425): 1219-1221.

36. Salisbury C, Sampson F, Ridd M, Montgomery AA. How should continuity of care in primary health care be assessed? Br J Gen Pract 2009; 59(561): e134-e141. 
Appendix 1. Expanded diagnostic clusters ${ }^{a}$ within the ACG ${ }^{\circledR}$ system, designated by the authors as chronic conditions.

\begin{tabular}{|c|c|}
\hline Expanded diagnostic cluster code & Label \\
\hline $\begin{array}{l}\text { Not an EDC. Itemised separately } \\
\text { within the ACG software }\end{array}$ & Asthma \\
\hline $\begin{array}{l}\text { Not an EDC. Itemised separately } \\
\text { within the ACG software }\end{array}$ & Hypertension \\
\hline $\begin{array}{l}\text { Not an EDC. Itemised separately } \\
\text { within the ACG software }\end{array}$ & Diabetes \\
\hline $\begin{array}{l}\text { Not an EDC. Itemised separately } \\
\text { within the ACG software }\end{array}$ & Arthritis \\
\hline ADM02 & $\begin{array}{l}\text { Surgical aftercare } \\
\text { (e.g. heart valve replacement, colostomy) }\end{array}$ \\
\hline ADM03 & $\begin{array}{l}\text { Transplant status } \\
\text { (e.g. heart transplant, bone marrow transplant) }\end{array}$ \\
\hline ALL06 & Disorders of the immune system \\
\hline CAR03 & $\begin{array}{l}\text { Ischemic heart disease } \\
\text { (excluding acute myocardial infarction) }\end{array}$ \\
\hline CAR04 & Congenital heart disease \\
\hline CAR05 & Congestive heart failure \\
\hline CAR06 & Cardiac valve disorders \\
\hline CAR07 & Cardiomyopathy \\
\hline CAR09 & Cardiac arrhythmia \\
\hline CAR10 & Generalsed atherosclerosis \\
\hline CAR11 & Disorders of lipoid metabolism \\
\hline CAR12 & Acute myocardial infarction \\
\hline CAR16 & $\begin{array}{l}\text { Cardiovascular disorders, other } \\
\text { (e.g. sub-acute bacterial endocarditis) }\end{array}$ \\
\hline EAR08 & Deafness, hearing loss \\
\hline END02 & Osteoporosis \\
\hline END04 & Thyroid disease \\
\hline END05 & $\begin{array}{l}\text { Other endocrine disorders } \\
\text { (including diabetes insipidus) }\end{array}$ \\
\hline EYE02 & Blindness \\
\hline EYE03 & $\begin{array}{l}\text { Retinal disorders } \\
\text { (excluding diabetic retinopathy) }\end{array}$ \\
\hline EYE06 & Cataract, aphakia \\
\hline EYE08 & Glaucoma \\
\hline EYE13 & Diabetic retinopathy \\
\hline FRE03 & Endometriosis \\
\hline FRE12 & Utero-vaginal prolapse \\
\hline GAS02 & Inflammatory bowel disease \\
\hline GAS05 & Chronic liver disease \\
\hline GAS08 & Gastro-oesophageal reflux \\
\hline GAS09 & Irritable bowel syndrome \\
\hline GAS10 & Diverticular disease colon \\
\hline GAS12 & Chronic pancreatitis \\
\hline GAS13 & Lactose intolerance \\
\hline GSU06 & Chronic cystic disease of the breast \\
\hline GSU08 & Varicose veins of lower extremities \\
\hline GSU11 & Peripheral vascular disease \\
\hline GSU13 & Aortic aneurysm \\
\hline GTC01 & Chromosomal anomalies \\
\hline
\end{tabular}




\begin{tabular}{|c|c|}
\hline Expanded Diagnostic Cluster code & Label \\
\hline GTC02 & Inherited metabolic disorders \\
\hline GUR01 & Vesicoureteral reflux \\
\hline GUR03 & Hypospadias, other penile anomalies \\
\hline GUR04 & Prostatic hypertrophy \\
\hline GUR09 & Renal calculi \\
\hline GUR10 & Prostatitis \\
\hline HEM01 & Hemolytic anaemia \\
\hline HEM02 & Iron deficiency, other deficiency anaemias \\
\hline HEM05 & Aplastic anaemia \\
\hline HEM03 or HEM 06 & $\begin{array}{l}\text { Thromboplebitis and DVT } \\
\text { (deep vein thrombosis) }\end{array}$ \\
\hline HEM07 & Hemophilia, coagulation disorder \\
\hline HEM08 & $\begin{array}{l}\text { Hematologic disorders, other } \\
\text { (including secondary polycythaemia) }\end{array}$ \\
\hline INF01 & Tuberculosis \\
\hline INF04 & HIV, AIDS \\
\hline MAL01 & Malignant neoplasms of the skin \\
\hline MAL02 & Low impact malignant neoplasms \\
\hline MAL03 & High impact malignant neoplasms \\
\hline MAL04 & Malignant neoplasms, breast \\
\hline MAL05 & Malignant neoplasms, cervix, uterus \\
\hline MAL06 & Malignant neoplasms, ovary \\
\hline MAL07 & Malignant neoplasms, esophagus \\
\hline MAL08 & Malignant neoplasms, kidney \\
\hline MAL09 & Malignant neoplasms, liver and biliary tract \\
\hline MAL10 & Malignant neoplasms, lung \\
\hline MAL11 & Malignant neoplasms, lymphomas \\
\hline MAL12 & Malignant neoplasms, colorectal \\
\hline MAL13 & Malignant neoplasms, pancreas \\
\hline MAL14 & Malignant neoplasms, prostate \\
\hline MAL15 & Malignant neoplasms, stomach \\
\hline MAL16 & Acute leukemia \\
\hline MAL18 & Malignant neoplasms, bladder \\
\hline MUS06 & Kyphoscoliosis \\
\hline MUS07 & Congenital hip disclocation \\
\hline MUS11 & $\begin{array}{l}\text { Congenital anomalies of limbs, hands, } \\
\text { and feet }\end{array}$ \\
\hline MUS13 & Cervical pain syndromes \\
\hline MUS14 & Low back pain \\
\hline NUR03 & Peripheral neuropathy, neuritis \\
\hline NUR05 & Cerebrovascular disease \\
\hline NUR06 & Parkinson's disease \\
\hline NUR07 & Seizure disorder \\
\hline NUR08 & Multiple sclerosis \\
\hline NUR09 & Muscular dystrophy \\
\hline NUR11 & Dementia and delirium \\
\hline NUR12 & Quadriplegia and paraplegia \\
\hline NUR16 & Spinal cord injury/disorders \\
\hline
\end{tabular}


Appendix 1 continued. Expanded diagnostic clusters ${ }^{\mathrm{a}}$ within
the $A C \mathrm{G}^{\circledR}$ system, designated by the authors as chronic conditions.

Expanded Diagnostic Cluster code Labe

\begin{tabular}{ll}
\hline NUR17 & Paralytic syndromes, other \\
\hline NUR18 & Cerebral palsy \\
\hline NUR19 & Developmental disorder \\
\hline NUR21 & $\begin{array}{l}\text { Neurologic disorders, other } \\
\text { (e.g. Huntingdon's chorea) }\end{array}$ \\
\hline NUT03 & Obesity \\
\hline PSY01 & Anxiety, neuroses \\
\hline PSY02 & Substance use \\
\hline PSY04 & Behaviour problems \\
\hline PSY05 & Attention deficit disorder \\
\hline PSY07 & Schizophrenia and affective psychosis \\
\hline PSY08 & Personality disorders \\
\hline PSY09 & Depression \\
\hline REC01 & Cleft lip and palate \\
\hline REC03 & Chronic ulcer of the skin \\
\hline REN01 & Chronic renal failure \\
\hline REN04 & Nephritis, nephrosis \\
\hline REN05 & Renal disorders, other \\
\hline RES03 & Cystic fibrosis \\
\hline RES04 & Emphysema, chronic bronchitis, COPD \\
\hline (chronic obstructive pulmonary disease)
\end{tabular}

aDetails of expanded diagnostic clusters (EDCs) obtained from the Johns Hopkins University Adjusted Clinical Groups (ACG) Case-Mix System Reference Manual version $7 .{ }^{17}$ Bloomberg: John Hopkins University, 2005. Copyright, used by permission. 